\title{
Intensidade de radiação influenciando características morfofisiológicas em folhas de Tetradenia riparia (Hochst.) Codd ${ }^{1}$
}

\author{
Laís Lima Nabuco Araújo², Hyrandir Cabral de Melo², \\ Gabriel Luis Castiglioni ${ }^{3}$ \& Letícia Almeida Gonçalves²
}

\author{
1 Parte da dissertação do primeiro autor, Programa de Pós-graduação em Biodiversidade Vegetal, Universidade Federal de Goiás, Brasil. \\ 2 Universidade Federal de Goiás, Departamento de Botânica, campus Samambaia, \\ Av. Esperança, s/n, CEP 74690-900, Goiânia, GO, Brasil. hyrandir@yahoo.com.br \\ 3 Universidade Federal de Goiás, Escola de Agronomia, Campus Samambaia, Av. Esperança, s/n, CEP 74690-900, Goiânia, GO, Brasil.
}

Recebido em 16.X. 2015

Aceito em 17. IV. 2019

DOI 10.21826/2446-82312019v74e2019001

RESUMO - Com o objetivo de estudar o papel da luz sobre o desenvolvimento de Tetradenia riparia avaliaram-se características morfofisiológicas quando cultivada sob $30 \%, 50 \%$ e $80 \%$ de sombreamento e a pleno sol. A espessura do limbo foliar foi maior em plantas cultivadas a pleno sol. A área foliar foi maior em plantas cultivadas a $80 \%$ de sombreamento. Teores de clorofila "a" e total, carotenoides, proteínas e nitrogênio foram maiores nas plantas cultivadas a $50 \%$ e $80 \%$ de sombreamento. Não ocorreram diferenças para densidade estomática e tricomas na epiderme abaxial, nos teores de clorofila "b" e razão clorofila a/b e valores de cinzas entre plantas cultivadas nos diferentes tratamentos. A densidade estomática foi maior na epiderme adaxial de plantas cultivadas a $30 \%$ de sombreamento. O teor de lipídios foi menor nas plantas crescidas a $80 \%$ de sombreamento. $T$. riparia tem alta plasticidade morfofisiológica a ambientes com diferentes intensidades de radiação.

Palavras-chave: fotomorfogênese, luz, planta medicinal

ABSTRACT- Radiation intensity influencing morphophysiological characteristics in leaves of Tetradenia riparia (Hochst.) Codd. This work aimed to study the role of light on Tetradenia riparia development. Tetradenia riparia (Hochst.) Codd.'s morphophysiological characteristics were evaluated when cultivated under $30 \%, 50 \%$ and $80 \%$ shading levels and at full sunlight. The leaf thickness was higher in plants grown under full sunlight. The leaf area was larger in plants cultivated under $80 \%$ of shade. Chlorophyll "a" and total, carotenoids, proteins and nitrogen were higher in plants cultivated under $50 \%$ and $80 \%$ of shade. There were no differences for stomata density and trichomes in the abaxial epidermis, content of chlorophyll "b," chlorophyll a/b ratio and ash content among plants of different treatments. The stomata density of the adaxial epidermis was higher in plants cultivated under $30 \%$ of shade. The lipid content was lower in plants grown under $80 \%$ of shade. T. riparia has high morphophysiological plasticity to different radiation intensities.

Keywords: light, medicinal plant, photomorphogenesis

\section{INTRODUÇÃO}

Tetradenia riparia (Hochst.) Codd (Lamiaceae) é utilizada popularmente como planta medicinal no tratamento de doenças como malária, angina, doença tropical de pele, gastroenterites, gonorreia, diarreia, abscessos dentários, dores de cabeça, bronquites, tosses, úlceras, esterilidade feminina, doenças renais e febres (Van Puyelde et al. 1986). Estudos laboratoriais confirmam suas propriedades antimicrobianas contra Candida albicans, Shigella dysenteriae e Streptococcus pyogenes (Van Puyelde et al. 1986). No Brasil, a espécie T. riparia também é utilizada como planta ornamental e é conhecida popularmente como incenso, lavândula, limonete, plumade-névoa ou falsa-mirra (Martins et al. 2008).

É de conhecimento comum que a luz influencia fortemente o desenvolvimento de plantas, sendo fundamental ao processo fotossintético e aos eventos relacionados à fotomorfogênese. Também é conhecido o seu papel como fator modulador na transcrição gênica.

Estima-se que a luz branca influencia a expressão de $20 \%$ do genoma em plântulas de arroz e Arabidopsis (Jiao et al. 2005), o que evidencia sua importância sobre o metabolismo vegetal como um todo, incluindo a produção de metabólitos secundários.

Embora a radiação seja um fator elicitor, inibidor ou modulador para a biossíntese de diferentes substâncias de interesse farmacológico (Sales et al. 2009, Mattana et al. 2010), poucos estudos exploram sua importância para o cultivo racional de plantas medicinais.

Alterações na disponibilidade de radiação influenciam diretamente na concentração de pigmentos fotossintéticos, alterando a quantidade de clorofila total, assim como a razão de clorofila "a" em relação à clorofila "b" (Whatley \& Whatley 1982) e carotenoides (Demmig-Adams 2006), promovendo mudanças diretas sobre a fotossíntese 
líquida, e consequentemente sobre a disponibilidade de fotoassimilados para o crescimento das plantas (Boardman 1977, Ferreira et al. 2012). A disponibilidade de radiação também influencia o conteúdo de lipídios, nitrogênio, proteínas e cinzas nos tecidos vegetais, cujos teores variam de acordo com a adaptação ou tolerância dos diferentes genótipos à condição de sol e sombra (Meletiou-Christou et al. 1994, Poorter et al. 2006).

Além de aspectos fisiológicos, muitas características anatômicas são influenciadas pela disponibilidade de radiação, a exemplo da densidade estomática, número e tamanho das células epidérmicas, número de tricomas, tamanho dos espaços intercelulares e esclerificação de tecidos (Nery et al. 2007). Alterações quantitativas de diferentes parâmetros anatômicos observadas em células e tecidos vegetais são consideradas importantes, seja para otimização de suas funções devido a uma baixa disponibilidade de radiação em plantas que requerem altas taxas de radiação, seja para reduzir a possibilidade de danos fotoxidativos, ou minimizar seus efeitos, causados pelo excesso de radiação especialmente em plantas que requerem baixas taxas de radiação para o seu desenvolvimento (Fails et al. 1982, Hoflacher \& Bauer 1982).

A integração de estudos anatômicos e fisiológicos é fundamental para investigações que visam o estudo de fatores ambientais influenciando o desenvolvimento das plantas. Este trabalho teve como objetivo avaliar a composição centesimal da massa seca, a concentração de pigmentos fotossintéticos, assim como área foliar, espessura e densidade de tricomas e estômatos em folhas de T. riparia cultivada sob diferentes intensidades de radiação luminosa.

\section{MATERIAL E MÉTODOS}

Plantas de T. riparia foram obtidas no Horto de Plantas Medicinais da Empresa de Assistência Técnica e Extensão Rural do Estado de Goiás, EMATER-GO, as quais foram propagadas por estaquia e cultivadas em sacos plásticos contendo $3 \mathrm{~L}$ de substrato comercial Plantmax ${ }^{\circledR}$. As plantas foram cultivadas no Instituto de Ciências Biológicas da Universidade Federal de Goiás, Goiânia, GO, situada a $16^{\circ} 36^{\prime \prime} \mathrm{S}$ e $49^{\circ} 13^{\prime \prime} \mathrm{W}$, e altitude de aproximadamente $800 \mathrm{~m}$. Após o estabelecimento de três folhas maduras, as plantas foram cultivadas sob mini-telados completamente cobertos com telas de polietileno pretas comercializadas para proporcionar níveis de sombreamento de $30 \%, 50 \%$ e $80 \%$ e cultivadas também a pleno sol, constituindo os tratamentos. Foi utilizado um porômetro LI-1600 para quantificar o percentual efetivo de radiação incidente no interior dos mini-telados onde as plantas foram cultivadas. As leituras foram realizadas ao meio dia na altura da copa das plantas, e os dados foram comparados ao ambiente externo. A tela comercializada para prover $30 \%$ de sombreamento estava retendo $38 \%$ da radiação fotossinteticamente ativa; a de $50 \%$ estava retendo $45 \%$; a de $80 \%$ estava retendo $68 \%$.
Aos 30 dias e aos 60 dias de cultivo, o substrato foi suplementado com $5 \mathrm{~g}$ de NPK 4-14-8. As plantas foram regadas diariamente. $\mathrm{O}$ experimento foi conduzido em delineamento experimental inteiramente casualizado. Vinte plantas foram cultivadas em cada tratamento de sombreamento $(30,50$ e $80 \%)$ e a pleno sol.

Para as análises anatômicas, foi coletada uma folha do quinto nó abaixo do ápice de cinco plantas de cada tratamento, tomadas ao acaso, as quais estavam submetidas a 150 dias de exposição aos diferentes tratamentos. As folhas foram fixadas em solução FAA 70 (Johansen 1940) por 24 horas e posteriormente conservadas em solução de etanol a $70 \%$. Para todos os parâmetros anatômicos foram avaliados quatro campos por folha, perfazendo um total de 20 campos por tratamento. Para a determinação da espessura da lâmina foliar, foram utilizados cortes transversais, obtidos à mão livre, clarificados com água sanitária comercial e corados com azul de astra $0,3 \%$ e fucsina básica $0,1 \%$, posteriormente montados entre lâmina e lamínula contendo glicerina 50\% (Kraus \& Arduim 1997), os quais foram observados em um fotomicroscópio LEICA DM 500 acoplado a computador com software AxioVision Zeiss. Amostras diafanizadas foram usadas para determinar a densidade de estômatos e de tricomas. Para o processo de diafanização, foram retirados fragmentos de $0,5 \times 0,5 \mathrm{~cm}$ no terço médio da lâmina foliar, e o procedimento foi realizado segundo Johansen (1940, modificado), sendo as amostras submetidas à solução de $\mathrm{NaOH} 10 \%$ por $3 \mathrm{~h}$, posteriormente clarificadas em solução de hipoclorito de sódio a 5\%, seguidas de imersão em cloral hidratado $(\mathrm{CCl} 3 \mathrm{CHOH} 2 \mathrm{O})$ $10 \%$ até que o material ficasse totalmente translúcido. Após lavadas, as amostras foram imersas em safranina aquosa $0,1 \%$ (por aproximadamente $24 \mathrm{~h}$ ) e montadas entre lâmina e lamínula contendo glicerina 50\%. A densidade de estômatos e de tricomas foi determinada segundo a metodologia de Labouriau et al. (1961) utilizando-se fotomicroscópio Zeiss MC 80 com o auxílio de uma câmara clara.

Para área foliar, foram utilizadas três plantas por tratamento, aos 150 dias de cultivo, das quais foram coletadas folhas do primeiro ao quinto nó. A avaliação foi realizada com um medidor de área foliar modelo LICOR-3000.

Para as análises de lipídios, nitrogênio total, proteínas totais e cinzas foram coletadas folhas do quinto ao décimo nó em plantas com 120 dias tratamento, sendo utilizadas amostras de plantas diferentes, para cada tratamento, para realização das repetições analíticas, as quais foram realizadas em triplicata. Após a coleta, foram colocadas na estufa a $105^{\circ}$ para secagem. O teor de gordura e cinzas foi realizado segundo o método de extração por Soxhlet, descrito nas Normas Analíticas do Instituto Adolf Lutz (2008), tendo sido utilizados três gramas de material foliar. Para o teor de nitrogênio total e proteínas totais, foi utilizada a metodologia de Kjeldahl (1883). Para o teor de proteínas totais, utilizaram-se os valores obtidos para nitrogênio e multiplicou-se pelo fator de conversão 6,25 (AOAC, 1970). 
Na extração e quantificação das clorofilas, "a", "b", total e carotenoides, foram utilizadas três plantas por tratamento e de cada planta foram coletadas cinco folhas do quinto ao oitavo nó, às 7 horas da manhã, em plantas com 120 dias de tratamento. Foram feitas análises em triplicata de cada planta a partir de $1 \mathrm{~g}$ de massa fresca oriunda do terço médio foliar. As análises de clorofila seguiram o método de Arnon (1949) e de carotenoides o método de Lichtenthaler (1987). Os dados foram submetidos à análise de variância e as médias foram comparadas pelo teste de Tukey a $5 \%$ de probabilidade.

\section{RESULTADOS E DISCUSSÃO}

A área foliar das plantas crescidas a $80 \%$ de sombreamento foi significativamente maior, seguida pela área foliar das plantas submetidas ao tratamento de 50\% de sombreamento. Entretanto, a espessura do limbo foi maior nas folhas das plantas cultivadas no tratamento a pleno sol (Tab. 1).

Uma característica marcante de folhas crescidas à sombra, quando comparadas às folhas desenvolvidas a pleno sol, é uma maior área foliar seguida de redução na espessura do limbo foliar (Rossato et al. 2010, Santos et al. 2014), tal qual observado neste estudo. A redução na espessura do limbo foliar, concomitante ao aumento da área foliar, comumente ocorre em função de diminuição na espessura do parênquima paliçádico e esponjoso (Hoflacher \& Bauer 1982, Terashima et al. 2001). Esse comportamento ocorre no intuito de otimizar a captação da radiação na condição de sombreamento, o que contribui para uma melhor absorção da radiação pelos tecidos do mesofilo, aumentando a presença de tecidos fotossintetizantes expostos a condição ótima de radiação, e também evita possíveis prejuízos aos eventos metabólicos ou de desenvolvimento da planta dependentes de luz (Ptushenko et al. 2016, Rossato et al. 2010). O aumento da espessura do limbo foliar na condição de pleno sol ocorre em função de modificações no padrão de expansão de células do mesofilo, alongando-se, ou do aumento do número de células do parênquima paliçádico no intuito de otimização da captação e distribuição da luz (Kim et al. 2005, Terashima et al. 2001). Diferentes espécies como Passiflora edulis Sims, Passiflora edulis f. flavicarpa Deg. (Passifloraceae), Vigna unguiculata L. Walp (Fabaceae), Cupania vernalis Camb. (Sapindaceae) e Mikania glomerata Sprengel (Asteraceae) têm sido observadas com comportamento similar ao encontrado neste estudo para área foliar e espessura do limbo foliar (Castro et al. 2007, Lima Júnior et al. 2006, Santos et al. 2011, Zanella et al. 2006 ).

Tabela 1. Características morfofisiológicas de folhas de Tetradenia riparia (Hochst.) Codd cultivada em diferentes níveis de sombreamento.

\begin{tabular}{|c|c|c|c|c|}
\hline \multirow{2}{*}{ Características avaliadas } & \multicolumn{4}{|c|}{ Níveis de sombreamento } \\
\hline & Pleno sol & $30 \%$ & $50 \%$ & $80 \%$ \\
\hline Área foliar $\left(\mathrm{cm}^{2}\right)$ & $7,22 \mathrm{c} \pm 0,37$ & $7,86 \mathrm{c} \pm 0,42$ & $10,84 \mathrm{~b} \pm 0,24$ & $13,05 \mathrm{a} \pm 0,29$ \\
\hline Espessura do limbo foliar $(\mu \mathrm{m})$ & $379,41 \mathrm{a} \pm 0,25$ & $340,11 b \pm 0,14$ & $339,35 \mathrm{~b} \pm 0,24$ & $348,29 b \pm 0,10$ \\
\hline Estômatos $\left(\mathrm{n}^{\mathrm{o}} / \mathrm{mm}^{2}\right)$ - Ep. abaxial & $171 \mathrm{a} \pm 0,33$ & $159 \mathrm{a} \pm 0,47$ & $182 \mathrm{a} \pm 0,31$ & $163 \mathrm{a} \pm 0,46$ \\
\hline Estômatos ( $\left.\mathrm{n}^{\mathrm{o}} / \mathrm{mm}^{2}\right)$ - Ep. adaxial & $41 \mathrm{~b} \pm 1,11$ & $87 \mathrm{a} \pm 1,08$ & $22 \mathrm{c} \pm 2,5$ & $30 \mathrm{~b} \pm 3,75$ \\
\hline Tricomas $\left(\mathrm{n}^{\circ} / \mathrm{mm}^{2}\right)$ Ep. Abaxial & $150 \mathrm{a} \pm 0,65$ & $95 \mathrm{a} \pm 0,80$ & $95 \mathrm{a} \pm 0,59$ & $117 \mathrm{a} \pm 0,96$ \\
\hline Tricomas $\left(\mathrm{n}^{\circ} / \mathrm{mm}^{2}\right)$ Ep. Adaxial & $53 \mathrm{a} \pm 0,35$ & $53 \mathrm{a} \pm 0,35$ & $83 \mathrm{a} \pm 0,68$ & $64 \mathrm{a} \pm 0,88$ \\
\hline Clorofila a (mg/g MF) & $0,83 b \pm 0,23$ & $0,86 \mathrm{~b} \pm 0,05$ & $1,18 \mathrm{a} \pm 0,31$ & $1,19 \mathrm{a} \pm 0,46$ \\
\hline Clorofila b (mg/g MF) & $0,25 \mathrm{a} \pm 0,36$ & $0,26 \mathrm{a} \pm 0,53$ & $0,32 \mathrm{a} \pm 0,59$ & $0,32 \mathrm{a} \pm 0,31$ \\
\hline Razão clorofila a/b (mg/g MF) & $3,34 \mathrm{a} \pm 0,59$ & $3,43 \mathrm{a} \pm 0,41$ & $3,94 \mathrm{a} \pm 0,79$ & $3,84 \mathrm{a} \pm 0,79$ \\
\hline Clorofila total (mg/g MF) & $1,37 \mathrm{~b} \pm 0,31$ & $1,42 \mathrm{~b} \pm 0,19$ & $1,93 \mathrm{a} \pm 0,23$ & $1,95 \mathrm{a} \pm 0,44$ \\
\hline Carotenoides (mg/g MF) & $0,10 \mathrm{~b} \pm 0,20$ & $0,10 \mathrm{~b} \pm 0,10$ & $0,11 \mathrm{a} \pm 0,09$ & $0,13 \mathrm{a} \pm 0,33$ \\
\hline Cinzas $(\%)$ & $1,15 \mathrm{a} \pm 0,42$ & $1,27 \mathrm{a} \pm 0,39$ & $1,39 \mathrm{a} \pm 0,10$ & $1,30 \mathrm{a} \pm 0,06$ \\
\hline Lipídios (\%) & $6,33 \mathrm{a} \pm 0,01$ & $6,12 \mathrm{a} \pm 0,05$ & $6,07 \mathrm{a} \pm 0,11$ & $5,11 \mathrm{~b} \pm 0,06$ \\
\hline Nitrogênio total (\%) & $1,98 \mathrm{~b} \pm 0,15$ & $2,02 \mathrm{~b} \pm 0,10$ & $2,38 \mathrm{a} \pm 0,10$ & $2,46 \mathrm{a} \pm 0,04$ \\
\hline Proteínas totais (\%) & $12,43 \mathrm{~b} \pm 0,09$ & $12,64 \mathrm{~b} \pm 0,04$ & $14,95 \mathrm{a} \pm 0,10$ & $15,41 \mathrm{a} \pm 0,10$ \\
\hline
\end{tabular}

$\mathrm{Ep}=$ epiderme. Médias seguidas de mesma letra na linha não diferem entre si pelo teste Tukey, $p \leq 0,05$. As médias estão seguidas pelo percentual do coeficiente de variação.

Não foram observadas diferenças para a densidade de estômatos na epiderme abaxial e densidade de tricomas na epiderme abaxial e adaxial nas plantas de Tetradenia riparia cultivada nos diferentes níveis de sombreamento. No entanto, tanto a condição de pleno sol quanto a de $50 \%$ e $80 \%$ de sombreamento promoveram menor densidade estomática em relação ao tratamento de $30 \%$ de sombreamento na epiderme adaxial (Tab. 1), indicando que tanto o excesso quanto a deficiência no fluxo de radiação podem promover redução na densidade dessa estrutura epidérmica. Estes 
resultados corroboram, em parte, os trabalhos de Nery et al. (2007) e Lima Júnior et al. (2006), os quais verificaram que, em Calophyllum braziliense Cambess. e Cupania vernalis Camb., as folhas desenvolvidas a pleno sol possuíam maior densidade estomática se comparadas as folhas crescidas em condição sombreada, e também evidencia a influência do genótipo sobre esta característica. Tanto a densidade quanto o tamanho dos estômatos influenciam na transpiração das plantas, assim como maior densidade de tricomas pode reduzir a temperatura, pela reflexão luminosa, e a transpiração pela formação de um microclima mais úmido na camada limítrofe da folha (Boeger et al. 2009, Melo et al. 2007).

A formação e o desenvolvimento dos estômatos são regulados por um aparato de fotorreceptores, os quais respondem tanto a diferenças na intensidade quanto na qualidade da radiação, ambos fatores influenciados pelos tratamentos testados neste trabalho. Os fotorreceptores criptocromos, fitocromo A e fitocromo B, em associação, promovem o desenvolvimento dos estômatos (Kang et al. 2009). Neste sentido, percebe-se que tanto fotorreceptores responsivos à alta fluência de fótons quanto aqueles responsivos a baixa fluência, como fitocromos B e A, respectivamente, interagem entre si na promoção do desenvolvimento dos estômatos. Além da redução na intensidade da radiação, a sombra, por si só, já tem alteração na qualidade espectral da radiação, onde a razão da radiação vermelha:vermelho-distante diminui (Buisson \& Lee 1993), desfavorecendo a ação do fitocromo B e favorecendo a ação do fitocromo A.

Maiores teores de clorofila total, clorofila "a" e carotenoides observados nas condições de sombreamento, de $50 \%$ e $80 \%$ (Tab. 1) ocorrem como uma forma de adaptação à condição de sombra. De acordo com Engel \& Poggiani (1991) um dos fatores ligados à eficiência fotossintética e, consequentemente, ao crescimento e adaptabilidade a diversos ambientes é a presença de pigmentos foliares como as clorofilas "a", "b" e também os carotenoides. Segundo esses autores as folhas de sombra apresentam maior concentração de clorofila por grama de massa seca do que folhas expostas diretamente ao sol, assim, a combinação das clorofilas "a" e dos pigmentos acessórios possibilitam que as plantas captem maior quantidade de radiação solar fotossinteticamente ativa.

Resultados semelhantes aos observados neste trabalho para clorofilas totais e carotenoides (Tab. 1) foram encontrados em outros estudos, com as espécies Hymenaea courbaril L. (Leguminosae), submetida 0,30\%, $50 \%$ e $80 \%$ de sombreamento, Eugenia uniflora Linn (Myrtaceae), submetida a pleno sol e 50\% de luminosidade, Bombacopsis glabra (Pasq.) A. Robyns, submetida a pleno sol, $30 \%$ e $50 \%$ de sombreamento e Passiflora edulis Sims e Passiflora edulis f. flavicarpa Deg. (Passifloraceae), que foram estudadas em condições de sol e sombra (Lima et al. 2010, Martinazzo et al. 2007, Scalon et al. 2003, Zanella et al. 2006). Já Thayer \& Bjorkman (1990) observaram que os teores de carotenoides específicos que participam do ciclo da xantofila (violaxantina, zeaxantina e anteroxantina) são maiores em folhas crescidas ao sol, pela maior atuação destes carotenoides na dissipação de energia na forma de calor.

Em T. riparia, o teor de clorofila "b" e razão clorofila $\mathrm{a} / \mathrm{b}$ não diferiram entre os tratamentos (Tab. 1). Entretanto, segundo Ferreira et al. (2012), é comum maior proporção relativa de clorofila "b" em plantas sombreadas. Esse aumento possibilita a ampliação na capacidade de absorver diferentes comprimentos de onda e subsidia a transferência de energia para uma molécula específica de clorofila "a", que efetivamente toma parte das reações fotoquímicas da fotossíntese (Whatley \& Whatley 1982).

A diminuição na razão clorofila $\mathrm{a} / \mathrm{b}$, que comumente ocorre à medida que diminui a intensidade de radiação ocorre em função do enriquecimento do espectro vermelho distante (VD) nas condições de sombra. Isso provoca um aumento das reações do fotossistema II, o qual é mais rico em clorofila "b" que em clorofila "a" (Anderson 1986) e, provavelmente, atua como um sistema de aclimatização de plantas em ambientes enriquecidos com o espectro VD (Chow et al. 1990). A manutenção da razão clorofila a/b e clorofila "b" nas plantas em todos os tratamentos estudados neste trabalho é um indicativo de alta tolerância de $T$. riparia a diferentes condições de radiação.

Não houve diferenças significativas no percentual de cinzas em plantas submetidas a diferentes níveis de sombreamento (Tab.1). No entanto, em estudo realizado por Poorter et al. (2006), analisando plantas de dez diferentes espécies, o conteúdo de minerais observados em folhas aumentou de $30-41 \%$ em plantas crescidas em condições sombreadas. Provavelmente isso tenha ocorrido em função da redução do acúmulo comparativo de fotoassimilados em plantas crescidas à sombra em relação àquelas crescidas a pleno sol. A não variação no percentual de cinzas em $T$. riparia é mais um fator que denota sua alta plasticidade a condições de diferentes disponibilidades de radiação.

Plantas cultivadas no tratamento com $80 \%$ de sombreamento apresentaram menor percentual de lipídios (Tab. 1). Os percentuais de nitrogênio e proteínas totais foram maiores nas plantas crescidas a $50 \%$ e $80 \%$ de sombreamento, assim como observado em estudo realizado por Poorter et al. (2006) em que os teores destes compostos foram maiores em plantas crescidas à sombra. Comumente, tanto lipídios quanto nitrogênio e proteínas são compostos encontrados em maior concentração em folhas de plantas crescidas ao sol em comparação àquelas crescidas à sombra (Meletiou-Christou et al. 1994). O teor de nitrogênio geralmente está associado à capacidade fotossintética da planta (Bolton \& Brown 1980) estando alocado, para este fim, em proteínas e moléculas de clorofila. A capacidade fotossintética em plantas de sol tende a ser maior quando submetidas à condição de alta incidência de radiação, devido à alocação de nitrogênio em proteínas que participam do processo fotossintético, no entanto o conteúdo de clorofila tende a diminuir nas condições de pleno sol. Portanto, o maior acúmulo de nitrogênio nas 
condições de maior luminosidade é especialmente alocado em proteínas-chaves no processo fotossintético, como a rubisco (ribulose 1,5-bifosfato carboxilase-oxigenase), a qual concentra uma proporção média de $20 \%$ do total de nitrogênio foliar em plantas $\mathrm{C} 3$ em boas condições de nutrição (Evans \& Seeman 1984). Uma vez que, neste trabalho, se observou maior concentração de nitrogênio em plantas que apresentaram maior teor de clorofila total e clorofila "a" (Tab. 1), infere-se que haja um aumento de nitrogênio não-proteico alocado em clorofilas em plantas cultivadas nos tratamentos de $50 \%$ e $80 \%$ de sombreamento.

O conjunto de inalterações em função dos tratamentos, observado neste trabalho, como na razão clorofila a/b, clorofila "b", cinzas, densidade de tricomas em ambas as faces epidérmicas e de estômatos na epiderme abaxial, é indicativo de alta plasticidade morfofisiológica e de tolerância de T. riparia a diferentes condições de radiação.

\section{AGRADECIMENTOS}

À Fundação de Amparo à Pesquisa do Estado de Goiás (FAPEG) pela concessão de bolsa de mestrado ao primeiro autor durante o desenvolvimento deste trabalho.

\section{REFERÊNCIAS}

Anderson, J.M. 1986. Photoregulation of the composition, funtion and structure of thylacoid membranes. Annual Review of Plant Physiology Plant Molecular Biology 37:93-136.

Arnon, D. I. 1949. Copper enzymes in isolated chloroplast: polyphenoloxidase in Beta vulgaris. Plant Physiology 24:1-15.

Association of official and agricultural chemistry-AOAC. 1970. Official methods of analysis.. Eds. Horwitz, W. et al., AOAC, Washington, $1015 \mathrm{p}$.

Boardman, N.K. 1977. Comparative photosynthesis of sun and shade plants. Annual Review Plant Physiology 28:355-377.

Boeger, M.R.T., Júnior, A.E., Júnior, A.C., Reissmann, C.B., Alves, A.C.A \& Rickli, F.L. 2009. Variação estrutural foliar de espécies medicinais em consórcio com erva-mate, sob diferentes intensidades luminosas. Floresta 39:215-225.

Bolton, J.K. \& Brown, R.H. 1980. Photosyntesis of grass species differing in carbon dioxide fixation pathways V. response of Panicum maximum, panicum, milioides, and tall-fescues (Festuca arundinacea) to nitrogen nutrition. Plant Physiology 66:97-100

Buisson, D. \& Lee, D. W. 1993. The developmental response of papaya leaves to simulated canopy shade. American journal of Botany 80:947-952.

Castro, E.M., Pinto, J.E.B.P., Soares, A.M., Melo, H.C.; Bertalucci, S.K.V., Vieira, C.V. \& Júnior, E.C.L. 2007. Adaptações anatômicas de folhas de Mikania glomerata Sprengel (Asteraceae), em três regiões distintas da planta, em diferentes níveis de sombreamento. Revista Brasileira de Plantas Medicinais 9:8-16.

Chow, W.S., Melis, A. \& Anderson, J.M. 1990. Adjustments of phosystem stoichiometry in chloroplasts improve the quantum efficiency of photosynthesis. Proceedings of the National Academy of Sciences 87:7502-7506

Demmig-Adams, B. \& Adams, W.W. 2006. Photoprotection in an ecological context: the remarkable complexity of thermal energy dissipation. New Phytologist 172:11-21.

Engel, V.L. \& Poggiani, F. 1991. Estudo da concentração de clorofila nas folhas e seu espectro de absorção de luz em função do sombreamento em mudas de quatro espécies florestais nativas. Revista Brasileira de Fisiologia Vegetal 3:39-45.

Evans, J.R. \& Seeman, J.R. 1984. Differences between wheat genotypes in specific activity of RuBP carboxylase and the relationship to photosyntesis. Plant Physiology 74:759-765.
Fails, B.S., Lewis, A.J. \& Barden, J.A. 1982. Anatomy and morphology of sun and shade-grow Ficus benjamina. Journal of the American Society Horticultural Science 107:754-757.

Ferreira, W. N., Zandavalli, B., Bezerra, A. M. F. \& Filho, S.M. 2012. Crescimento inicial de Piptadenia stipulacea (Benth.) Ducke (Mimosaceae) e Anadenanthera colubrina (Vell.) Brenan var. cebil (Griseb.) Altshul (Mimosaceae) sob diferentes níveis de sombreamento. Acta Botanica Brasilica 26:408-414.

Hoflacher, H. \& Bauer, H. 1982. Light acclimation in leaves of the juvenile and adult life phases of ivy (Hedera helix). Physiologia Plantarum 56:177-182.

Instituto Adolf Lutz. 2008. Determinações Gerais. Normas Analíticas do Instituto Adolfo Lutz. Instituto Adolfo Lutz, São Paulo, 1020p.

Jiao, Y., Ma, L., Strickland, E. \& Denga, X.W. 2005. Conservation and divergence of light-regulated genome expression patterns during seedling development in rice and Arabidopsis. The Plant Cell 17:3239-3256.

Johansen, D. A. 1940. Plant microtechnique. McGraw-Hill Book Company, New York. 523p.

Kang, C. Y., Lian, H. L., Wang, F. F., Huang, J. R. \& Yang, H. Q. 2009. Cryptochromes, phytochromes, and COP1 regulate light-controlled stomatal development in Arabidopsis. The Plant Cell 21:2624-2641.

Kim, G.T., Yano, S., Kozuka, T. \& Tsukaya, K. 2005. Photomorfhogenesis of leaves: shade-avoidance and differentiation on sun and shade leaves. Photochemistry Photobiology Science 4:770-774.

Kjeldahl, J.Z. 1883. A new method for the determination of nitrogen in organic bodies. Analytical Chemistry 22: 366.

Kraus, J.E. \& Arduin, M. 1997. Manual básico de métodos em morfologia vegetal. Editora Universidade Federal Rural do Rio de Janeiro, Seropédica.198p.

Labouriau, L.G., Oliveira, J.G. \& Salgado, M.L. 1961. Transpiração de Schizolobium parahyba (Vell) Toledo I. Comportamento na estação chuvosa, nas condições de Caeté, Minas Gerais. Anais da Academia Brasileira de Ciência 23:237-257.

Lichtenthaler, H.K. 1987. Chlorophylls and carotenoids: pigments of photosynthetic biomembranes. In (Hochstrasser, M. Ed.) Methods in enzymology. New York: Academic, p. 350-382.

Lima Junior, E. C., Alvarenga, A. A. \& Castro, E. M. 2006. Physioanatomy traits of leaves in young plants of Cupania vernalis camb. subjected to different shading levels. Revista Árvore 30:33-41.

Lima, A.L.S., Zanella, F. \& Castro, L.D.M. 2010. Crescimento de Hymenaea courbaril L. var. stilbocarpa (Hayne) Lee et Lang. e Enterolobium contortisiliquum (Vell.) Morong (Leguminosae) sob diferentes níveis de sombreamento. Acta Amazônica 40:43-48.

Martinazzo, E.G., Anese, S., Wandscheer, A.C.D. \& Pastorini, L.H. 2007. Efeito do sombreamento sobre o crescimento inicial e teor de clorofila foliar de Eugenia uniflora Linn (Pitanga) - família Myrtaceae. Revista Brasileira de Biociências 5:162-164.

Martins, M.B.G., Martins, R.G.M. \& Cavalheiro, J.A. 2008. Histoquímica e atividade antibacteriana de folhas do incenso (Tetradenia riparia). Revista Biociências 14:127-140.

Mattana, R.S., Ribeiro, M.A., Marchese, J.A., Ming, L.C. \& Marques, M.O.M. 2010. Shade level effects on yield and chemical composition of the leaf essential oil of Pothomorphe umbellata (L.) Miquel. Scientia Agricola 67:414-418.

Meletiou-Christou, M., Rhizopoulou, S. \& Diamantoglu, S. 1994. Seasonal changes of carbohydrates, lipids and nitrogen content in sun and shade leaves from four mediterranean evergreen sclerophylls. Environmental and Experimental Botany 34:129-140.

Melo, H.C., Castro, E.M., Soares, A.M., Melo, L.A. \& Alves, J.D. 2007. Alterações anatômicas e fisiológicas em Setaria anceps Stapf ex Massey e Paspalum paniculatum L. sob condição de déficit hídrico. Hoehnea 34:145-153.

Nery, F.C., Alvarenga, A.A., Justo, C.F., Castro, E.M., Souza, G.S. \& Alves, E. 2007. Aspectos anatômicos de folhas de plantas jovens de Calophyllum brasiliense Cambess. submetidas a diferentes níveis de sombreamento. Revista Brasileira de Biociências 5:129-131.

Poorter, H., Pepin, S., Kijkers, T., Jong, Y., Evans, J. \& Korner, C. 2006. Construction costs, chemical composition and payback time of high- and low-irradiance leaves. Journal of Experimental Botany $57: 355-371$. 
Ptushenko, V.V., Ptushenko, O.S., Samoilova, O.P. \& Solovchenko, A. E. 2016.An exceptional irradiance-induced decrease of light trapping in two Tradescantia species: an unexpected relationship with the leaf architecture and zeaxanthin-mediated photoprotection. Biologia Plantarum 60:385-393.

Rossato, D. R., Takahashi, F. S. C., Silva, L. C. R. \& Franco, A. C. 2010. Características funcionais de folhas de sol e sombra de espécies arbóreas de uma mata de galeria no Distrito Federal, Brasil. Acta Botanica Brasilica 24:640-647.

Sales, J.F., Pinto, J.E.B.P., Ferri, P.H., Silva, F.G., Oliveira, C.B.A. \& Botrel, P.P. 2009. Influência do nível de irradiância no crescimento, produção e composição química do óleo essencial de hortelã-docampo (Hyptis marrubioides epl.). Semina: Ciências Agrárias 30: 389-396.

Santos, E.R., Borges, P.R.S., Siebeneichler, S.C., Cerqueira, A. P. \& Pereira, P.R. 2011. Crescimento e teores de pigmentos foliares em feijão-caupi cultivado sob dois ambientes de luminosidade. Revista Caatinga 24:14-19.

Santos, M.S., Feijó, N.S.A., Secco, T. M., Mielke, M. S., Gomes, F. P., Costa, L. C. B. \& Silva, D. C. 2014. Efeitos do sombreamento na anatomia foliar de Gallesia integrifolia (Spreng) Harms e Schinnus terebinthifolius Raddi. Revista Brasileira de Plantas Medicinais 16:89-96.

Scalon, S.P.Q., Mussury, R.M., Rigoni, M.R. \& Filho, H.S. 2003. Crescimento inicial de mudas de Bombacopsis glabra (pasq.) A. Robyns sob condição de sombreamento. Revista Árvore 27:753-758.

Terashima, I., Miyazawa, S.I. \& Hanba, Y.T. 2001. Why are sun leaves thicker than shade leaves? Consideration based on analyses of $\mathrm{CO}_{2}$ diffusion in the leaf. Journal Plant Research 114:93-105.

Thayer, S.S. \& Bjorkman, O. 1990. Leaf Xanthophyll content and composition in sun and shade determined by HPLC. Photosynthesis Research 23:331-343.

Van Puyvelde, L. \& De Kimpe, N. 1986. Active principles of Tetradenia riparia. I. Antimicrobial activity of 8(14), 15-sandaracopimaradiene7a,18-diol. Journal of Ethnopharmacology 17:269 - 275.

Whatley, F.H. \& Whatley, F.R. 1982. A luz e a vida das plantas. EPUEDUSP, São Paulo, 101p.

Zanella, F., Soncela, R. \& Lima, A.L.S. 2006. Formação de mudas de maracujazeiro "amarelo" sob diferentes níveis de sombreamento em Ji- Paraná/RO. Ciência e Agrotecnologia 30:880-884. 